\title{
Bud, leaf and stem essential oil composition of Syzygium aromaticum from Madagascar, Indonesia and Zanzibar
}

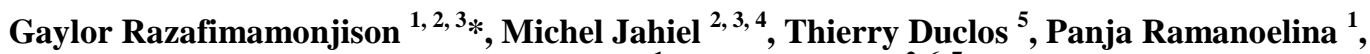 \\ Fanja Fawbush ${ }^{1}$, Pascal Danthu ${ }^{2,6,7}$ \\ ${ }^{1}$ Université d'Antananarivo, École Supérieure des Sciences Agronomiques, BP 175, Antananarivo, Madagascar \\ ${ }^{2}$ DP Forêts et Biodiversité, BP 853, Antananarivo, Madagascar \\ ${ }^{3}$ Centre Technique Horticole de Tamatave, BP 11, Tamatave, Madagascar \\ ${ }^{4}$ CIRAD, UPR Hortsys, PS4, Boulevard de la Lironde, 34392 Montpellier Cedex 05, France \\ ${ }^{5}$ Laboratoire QUIMDIS SAS, 71, rue Anatole France, 92300 Levallois-Perret, France \\ ${ }^{6}$ CIRAD, UR 105, Campus de Baillarguet, 34392 Montpellier Cedex 05, France \\ ${ }^{7}$ Directeur régional CIRAD Madagascar, Représentant d'Agreenium, BP 853, Antananarivo, Madagascar \\ *Corresponding author E-mail: rdinagaylor@yahoo.fr
}

Copyright $(92014$ Gaylor Razafimamonjison et al. This is an open access article distributed under the Creative Commons Attribution License, which permits unrestricted use, distribution, and reproduction in any medium, provided the original work is properly cited.

\begin{abstract}
Syzygium aromaticum essential oil is widely used in dental care, as an antiseptic and analgesic and is effective against a large number of bacteria. The major component of clove essential oils is usually considered to be eugenol, with $\beta$ caryophyllene and eugenyl acetate, being present although in lower concentrations. A review of published results reveals a great variability in the chemical composition of clove essential oils. The purpose of this study is to compare the chemical composition of Madagascar, Indonesia and Zanzibar bud, leaf and stem essential oils. 121 commercial essential oils isolated from bud, leaf and stem were used in this work. The oils were analyzed by GC and ten constituents were identified from the whole. The major constituent of Madagascar and Indonesia bud essential oils was eugenol (72.08 - 80.71\% and $77.32-82.36 \%$ respectively). Out of this constituent which was common to Madagascar and Indonesia bud essential oils, significant difference was observed with respect to eugenyl acetate $(11.68-21.32 \%$ vs $8.61-10.55 \%$ respectively) and $\beta$-caryophyllene $(2.76-6.38 \%$ vs $5.34-8.64 \%$ respectively). Comparing chemical composition of leaf essential oils from Madagascar with those of Indonesia, variation in the contents of main constituent, eugenol $(80.87-83.58 \%$ vs $75.04-77.54 \%)$, $\beta$-caryophyllene $(11.65-15.02$ vs $17.04-19.53 \%)$ and eugenyl acetate $(0.29-1.45 \%$ vs $0-0.06 \%)$ was observed. The major constituents of Madagascar, Indonesia and Zanzibar stem essential oils were eugenol (91.81 - 96.65\%, $88.76-89.28 \%$ and $87.52-89.47 \%$, respectively) and $\beta$-caryophyllene $(1.66-4.48 \%, 7.40-7.75 \%$ and $7.19-9.70 \%)$. For each plant material, variation in the percentage of the main constituents was observed according to the sample geographic origin.
\end{abstract}

Keywords: Anatomic origins; Chemical composition; Essential oils; Geographic origins; Syzygium aromaticum.

\section{Introduction}

The clove tree (Syzygium aromaticum Merrill \& Perry), Myrtaceae is a perennial tropical plant which grows to a height ranging from 10 to $20 \mathrm{~m}$, having large oval leaves and crimson flowers in numerous groups of terminal clusters. The clove tree is native to Moluccas Island (Indonesia) [1]. Two major products are available and marketed from clove tree: the clove which is the unopened green fully-grown buds, upon drying, and the essential oil extracted either from bud, leaf or stem [2].

In the early eighteenth century, the clove tree was introduced in different parts of the world: Zanzibar, India and Madagascar [3 - 5]. Today the most important producers of cloves are Indonesia (which is also, the main consumer), Tanzania (Zanzibar and Pemba islands) and Madagascar, which is the first world exporter with annual average exported quantities of 11000 tons for cloves and 1500 tons for essential oils [6]. 
Cloves can be used in cooking, either whole or in ground form. The spice is used throughout Europe and Asia and is smoked in cigarettes also known as "Kreteks" in Indonesia. Cloves are also an important incense material in Chinese and Japanese cultures [7].

The essential oil is widely used and well known for its medicinal properties. Traditional uses of clove oil include use in dental care as an antiseptic and analgesic [7, 8]. The oil is active against oral bacteria associated with dental caries and periodontal diseases [9] and is effective against a large number of other bacteria: Escherichia coli, Salmonella enteric [10] and Staphylococcus aureus [11 - 13]. Previous studies have reported antifungal [14], anticarcinogenic [15], antiallergic [8], antimutagenic [16], antioxidant [17] and insecticidal [18, 19] properties. The chief constituent of clove oil is eugenol, which is used as a starting material for the production of vanillin [20].

Research studies [20 - 23] carried out on bud, leaf and stem oil of S. aromaticum, from different parts of the world showed that the major component of these three types of clove oils is usually considered to be eugenol, followed by $\beta$ caryophyllene, $\alpha$-humulene, caryophyllene oxide and eugenyl acetate, although in different concentrations.

Recently, the effects of phenological stages on yield and composition of essential oil of S. aromaticum buds from Madagascar has been studied by Razafimamonjison et al. [22]. They found that eugenol was lower in the young bud stage $(39.66 \%)$ and increased in the subsequent phenological stages to reach maximum in the full fruiting stage $(94.89 \%)$. In contrast, eugenyl acetate was higher in the young bud stage $(56.07 \%)$, after which decreased to reach minimum in the full fruiting stage $(2.01 \%)$.

Other works carried out on the leaf essential oils of $S$. aromaticum show the variability of content of the major constituents. In the essential oils studied by Raina et al. [21] and Srivastava et al. [20], the principal constituent was eugenol ( 94.4 vs $82 \%$, respectively), followed by $\beta$-caryophyllene ( 2.9 vs $13 \%)$, $\alpha$-humulene $(0.3$ vs $1.5 \%)$ and eugenyl acetate (0 vs $0.4 \%)$.

Finally, little literature describes the chemical composition of clove stem essential oils. Gaydou et al. [23] assumed that eugenol (80.80\%), $\beta$-caryophyllene (10.5\%), $\alpha$-humulene $(1.26 \%)$ and eugenyl acetate $(4.40 \%)$ were the main compound of stem essential oils of $S$. aromaticum from Madagascar.

In all cases, papers demonstrated a great variability of chemical composition of $S$. aromaticum essential oil, without studying the determinants of this variability. As reported in the literature, for others species, such as Ravensara aromatica [24], Cedrelopsis grevei [25] and Cinnamosma fragrans [26], many factors such as the geographical origin, the plant material, the genetic factors and the season at which the plants were collected may be responsible for the chemical composition of the essential oil.

The purpose of this study is to compare the chemical composition of Madagascar, Indonesia and Zanzibar bud, leaf and stem essential oils.

\section{Materials and methods}

\subsection{Essential oil}

S. aromaticum essential oil used in this study were commercial samples provided by either industrial exporting companies of Madagascar, of Indonesia and of Zanzibar (Table 1). The essential oil samples were dried over anhydrous sodium sulfate $\left(\mathrm{Na}_{2} \mathrm{SO}_{4}\right)$ and stored in a cool and dark chamber until the analysis.

Table 1: $S$. aromaticum essential oil samples

\begin{tabular}{lccc}
\hline & & Anatomic origins & \\
\hline Geographic origins & Bud & Leaf & Stem \\
\hline Madagascar & 39 & 28 & 27 \\
Indonesia & 6 & 4 & 2 \\
Zanzibar & - & - & 15 \\
\hline Total & 45 & 32 & 44 \\
\hline
\end{tabular}

\subsection{Gas chromatography}

GC analyses were performed on a Varian gas chromatograph, model CP-3380, with flame ionization detectors fitted with two silica capillary columns: CP Sil 5 CB low bleed/MS (100\% dimethyl polysiloxane phase, Chrompack/Varian, Palo Alto, CA) capillary column $(30 \mathrm{~m} \times 0.25 \mathrm{~mm}$ i.d., $0.25 \mu \mathrm{m}$ film thickness) and Supelcowax 10 (polyethylene glycol), Supelco Inc, Bellefonte, PA) fused capillary column (30 $\mathrm{m} \times 0.25 \mathrm{~mm}$ i.d., $0.25 \mu \mathrm{m}$ film thickness); carrier gas, $\mathrm{N}_{2}$; flow rate, $0.8 \mathrm{ml} / \mathrm{min}$; injection type, split, $1: 100\left(0.2 \mu \mathrm{l}\right.$ pure essential oil); injector temperature, $220^{\circ} \mathrm{C}$; detector temperature, $250{ }^{\circ} \mathrm{C}$; temperature programme, $50-200{ }^{\circ} \mathrm{C}$ at $5{ }^{\circ} \mathrm{C} / \mathrm{min}$. The linear retention indices of the components were determined relative to the retention times of a series of n-alkanes and the percentage compositions were obtained from electronic integration measurements without taking into account relative response factors. All GC analyses on the apolar column were performed in triplicate, indicating a reproducibility of at least $3 \%$ in the relative percentages. 


\subsection{Identification and quantification of components}

Component identification was carried out by comparison of the retention data (determined relatively to the retention times of a series of n-alkanes) with those of the data library [27]. Quantitative analysis of each oil component, expressed in relative percentages of area, was carried out by peak area normalization measurements.

\subsection{Statistical analysis}

The distribution of the 121 samples was analyzed by Principal Component Analysis (PCA) using the XLSTAT Version 2012 statistical software package. The data set was composed of the values taken by the variables identified by GC and the 121 S. aromaticum essential oil samples. PCA was performed as it is among the best-known multivariate analysis methods for correlation variable determination [24, 25].

\section{Results and discussion}

\subsection{Chemical composition of bud, leaf and stem essential oils}

Bud essential oils (45 samples), leaf essential oils (32 samples) and stem essential oils (44 samples) were analyzed by GC. Ten constituents were identified and quantified, as shown in table 2. Great variability in the chemical compositions of the three essential oils was observed (Table 2). In all essential oils, eugenol was the major constituent, with increasing percentages from bud $(72.08-82.36 \%)$ to leaf $(75.04-83.58 \%)$ and to stem $(87.52-96.65 \%)$. In bud essential oils this compound is followed by eugenyl acetate $(8.61-21.32 \%)$, while in leaf and stem the latter was detected in considerably lower amounts $(0-1.45 \%$ and $0.07-2.53 \%$ respectively). In leaf essential oils, the second main compound was $\beta$-caryophyllene $(11.65-19.53 \%)$ less represented in bud essential oils $(2.76-8.64 \%)$ and in stem essential oils $(1.66-9.72 \%)$.

Table 2: Chemical composition (Relative percentages, extreme values) of bud, leaf and stem essential oils (In bolt: Discriminate components in each group).

\begin{tabular}{llccc}
\hline & & Group 1 & Group 2 & Group 3 \\
\hline $\mathrm{RI}^{\mathrm{a}}$ & Compounds & Bud & Leaf & Stem \\
\hline 1176 & methyl salicylate & $0-0.32$ & $\operatorname{tr}$ & $0-0.56$ \\
1241 & chavicol & $0-0.24$ & $0-0.13$ & $0-0.22$ \\
1348 & eugenol & $\mathbf{7 2 . 0 8 - \mathbf { 8 2 . 3 6 }}$ & $\mathbf{7 5 . 0 4 - 8 3 . 5 8}$ & $\mathbf{8 7 . 5 2 - \mathbf { 9 6 . 6 5 }}$ \\
1375 & $\alpha$-copaene & $0-0.27$ & $0-0.24$ & $0-0.27$ \\
1387 & methyl eugenol & $0-0.08$ & $0-0.24$ & $0-0.15$ \\
1420 & $\boldsymbol{\beta}$-caryophyllene & $2.76-8.64$ & $\mathbf{1 1 . 6 5 - 1 9 . 5 3}$ & $1.66-9.72$ \\
1453 & iso-eugenol & $0-0.24$ & $0-0.24$ & $0-0.83$ \\
1465 & a-humulene & $0.34-1.04$ & $1.38-2.17$ & $0.22-1.31$ \\
1494 & eugenyl acetate & $\mathbf{8 . 6 1 - 2 1 . 3 2}$ & $0-1.45$ & $0.07-2.53$ \\
1585 & caryophyllene oxide & $0.06-0.37$ & $0.05-0.55$ & $0.14-0.68$ \\
\hline${ }^{a}$ retention indices on CP Sil 5 column. tr: trace & & &
\end{tabular}

To highlight this variability in the chemical compositions of clove bud, leaf and stem essential oils, PCA were carried out on all 121 samples considering 10 variables (the 10 components identified by GC). The results of the statistical analysis were as follows:

The first two principal components (Fig.1) extracted by PCA explains $60.90 \%$ of the variability of which $37.69 \%$ was represented by $\mathrm{PC} 1$ and $23.21 \%$ by $\mathrm{PC} 2$. PC1 is principally structured by $\alpha$-humulene, $\beta$-caryophyllene and caryophyllene oxide with a positive correlation (0.88. 0.87 and 0.67 respectively) and one variable with negative correlation eugenyl acetate (- 0.80). PC2 is principally structured by eugenol with a positive correlation (0.94). 


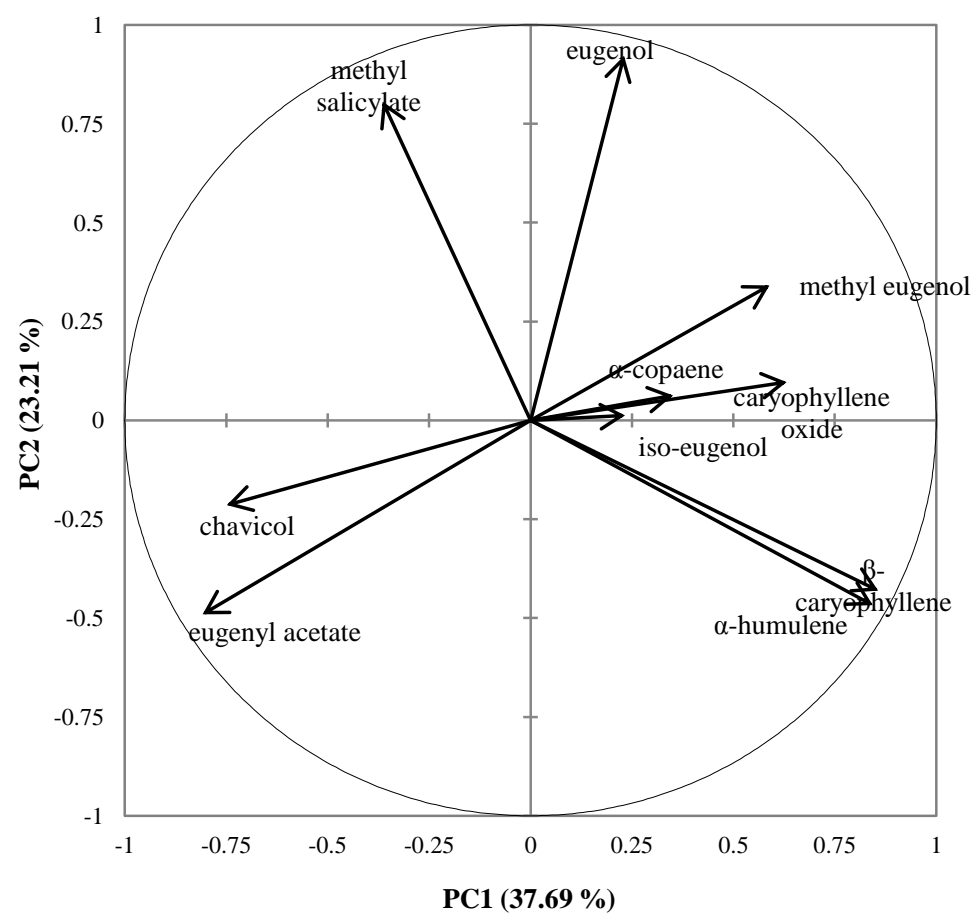

Fig. 1: Circle of correlations of the ten examined variables from bud, leaf and stem essential oils by the first two principal components (PC1/PC2).

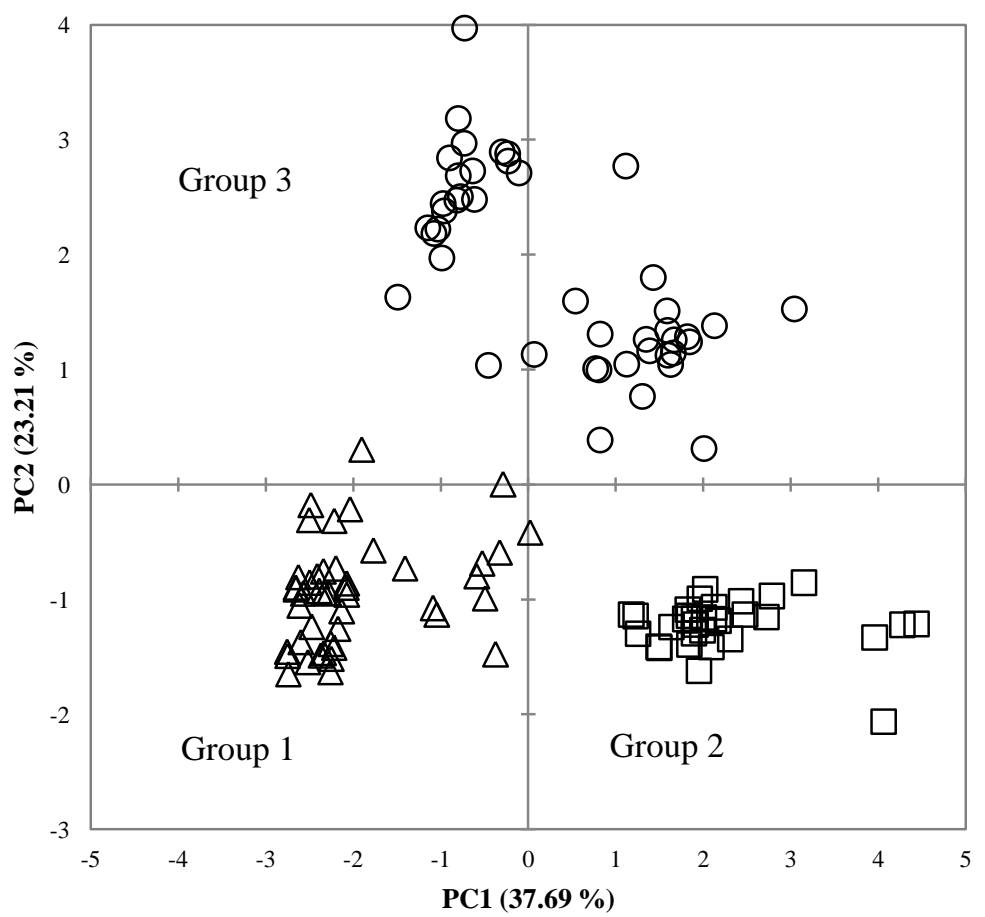

Fig. 2: Graphical representation of the 121 samples of essential oil from S. aromaticum using PCA according to PC1/PC2. Bud essential oils are represented by triangle (Group 1), leaf essential oils by square (Group 2) and stem essential oils by circle (Group 3).

The PCA according to planes PC1 and PC2 made it possible to distribute the 121 samples analyzed into three groups (Fig.2 and Table 2).

Group 1 is constituted by bud essential oils which are characterized by lower percentage of eugenol $(72.08-82.36 \%)$ and high content of eugenyl acetate $(8.61-21.32 \%)$. Group 2 is composed of leaf essential oils, mainly containing eugenol $(75.04-83.58 \%)$ and characterized by high content of $\beta$-caryophyllene $(11.65-19.53 \%)$. Group 3 , constituted by stem essential oils, is characterized by high eugenol content $(87.52-96.65 \%)$.

Taking into account our research, we can affirm that it is possible to use the percentage of eugenol, eugenyl acetate and $\beta$-caryophyllene to characterize the essential oil obtained from the different plant parts, bud, leaf and stem. 


\subsection{Comparison of the chemical composition of Madagascar and Indonesia bud essential oils}

Bud essential oils (39 samples from Madagascar and 6 from Indonesia) were analyzed by GC and ten constituents were identified and quantified, as shown in table 3. The major constituent of Madagascar and Indonesia bud essential oils was eugenol (72.08 - 80.71\% and $77.32-82.36 \%$ respectively). Out of this constituent which was common to Madagascar and Indonesia bud essential oils, significant difference was observed with respect to eugenyl acetate (11.68 $-21.32 \%$ vs $8.61-10.55 \%$ respectively) and $\beta$-caryophyllene $(2.76-6.38 \%$ vs $5.34-8.64 \%$ respectively) (Table 3 ).

To highlight this difference in the chemical composition of Madagascar and Indonesia bud essential oils, PCA were carried out on 45 samples combined, considering ten variables (The ten constituents identified by GC). The statistical analysis results were as follows:

\begin{tabular}{|c|c|c|c|}
\hline & & Group 1 & Group 2 \\
\hline RI & Compounds & Madagascar & Indonesia \\
\hline 1176 & methyl salicylate & $0-0.32$ & $0.04-0.16$ \\
\hline 1241 & chavicol & $0-0.24$ & $0.13-0.18$ \\
\hline 1348 & eugenol & $72.08-80.71$ & $77.32-82.36$ \\
\hline 1375 & $\alpha$-copaene & $0-0.11$ & $0.17-0.27$ \\
\hline 1387 & methyl eugenol & $0-0.06$ & $0.04-0.08$ \\
\hline 1420 & $\beta$-caryophyllene & $2.76-6.38$ & $5.34-8.64$ \\
\hline 1453 & iso-eugenol & $0-0.20$ & $0.02-0.24$ \\
\hline 1465 & $\alpha$-humulene & $0.34-1.04$ & $0.65-1.04$ \\
\hline 1494 & eugenyl acetate & $11.68-21.32$ & $8.61-10.55$ \\
\hline 1585 & caryophyllene oxide & $0.11-0.37$ & $0.06-0.32$ \\
\hline
\end{tabular}

The first two principal components (Fig. 3) extracted by PCA explained 53.98\% of the variability of which $38.02 \%$ was represented by $\mathrm{PC} 1$ and $15.96 \%$ by $\mathrm{PC} 2$. PC1 is principally structured by eugenyl acetate with a negative correlation ($0.82)$ and one variable with positive correlation $\beta$-caryophyllene $(0.84)$.

The PCA according to planes PC1 and PC2 made it possible to distribute the 45 samples of bud essential oils into two groups. In both groups, eugenol, $\beta$-caryophyllene and eugenyl acetate are also the major compounds, although in different amounts (Fig.4 and table 3).

Group 1, constituted by 39 samples from Madagascar was characterized by lower percentage of eugenol and $\beta$ caryophyllene (72.08 - 80.71\% and $2.76-6.38 \%$ respectively) and by higther content of eugenyl acetate (11.68$21.32 \%$ ). Group 2 is constituted by 6 samples from Indonesia. In this group, eugenol, $\beta$-caryophyllene and eugenyl acetate were detected at $77.32-82.36 \%, 5.34-8.64 \%$ and $8.61-10.55 \%$ respectively.

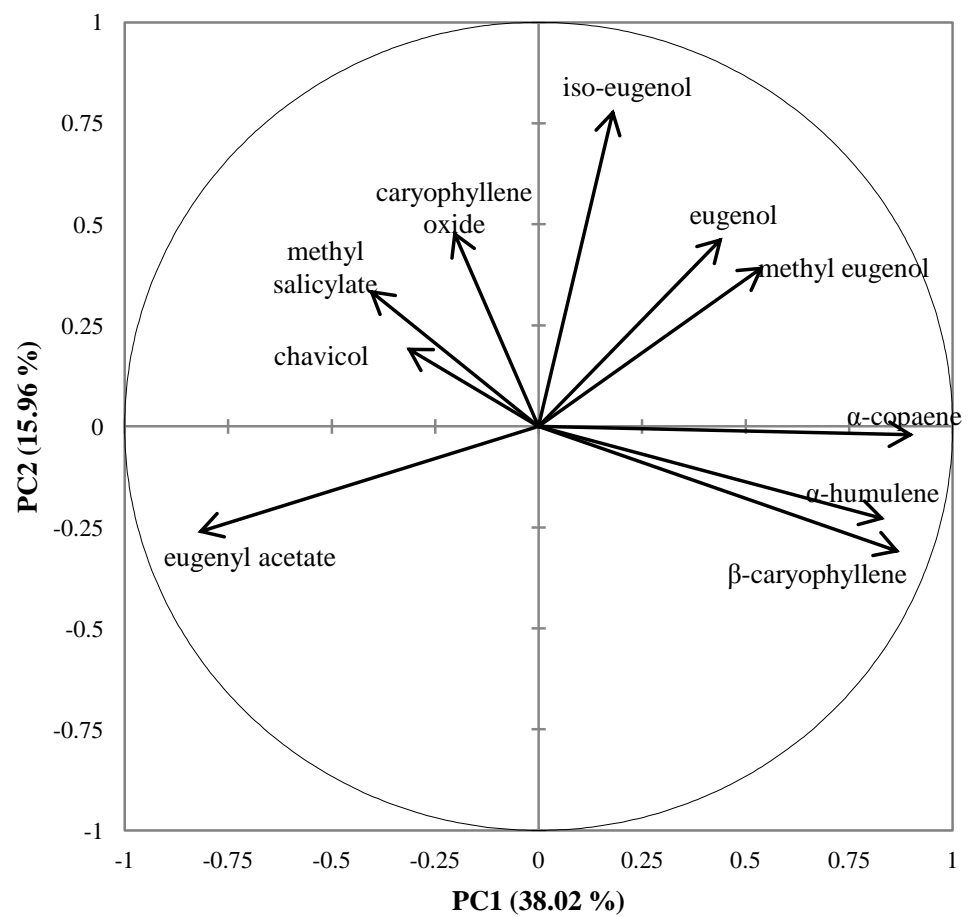

Fig. 3: Circle of correlations of the ten examined variables from bud essential oils by the first two principal components (PC1/PC2). 


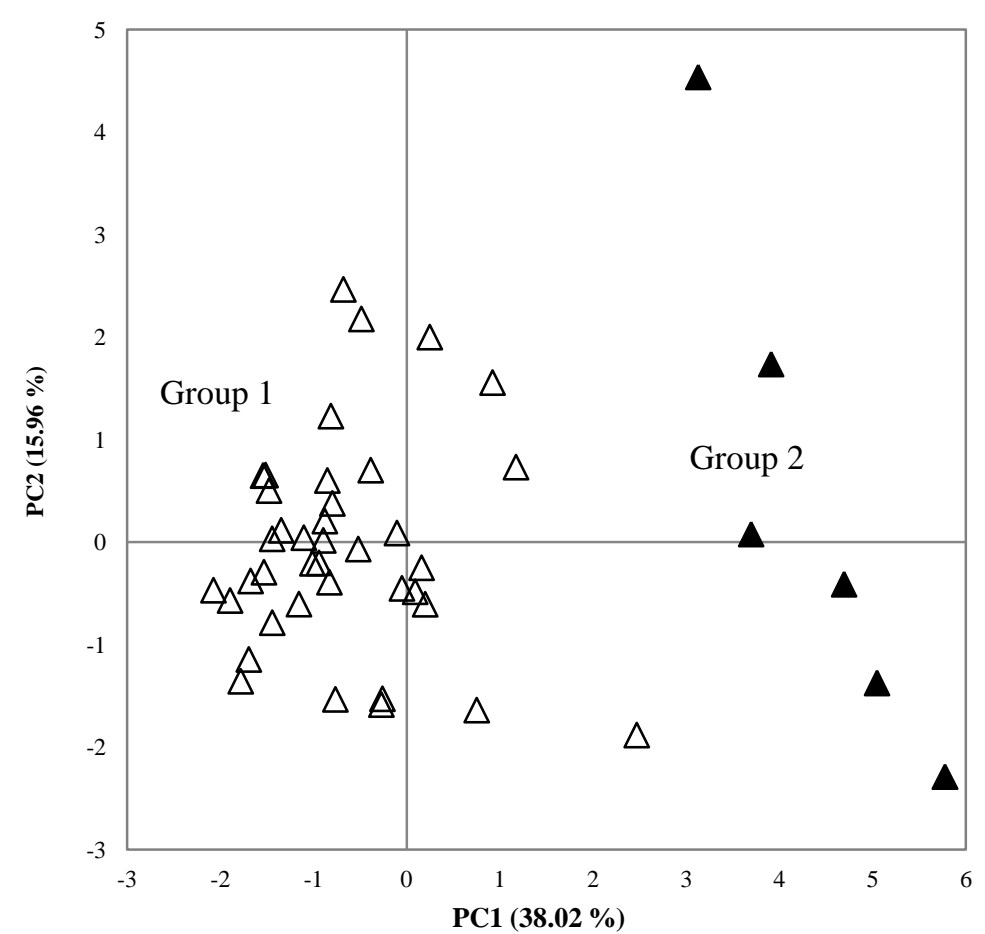

Fig. 4: Graphical representation of the 45 samples of bud essential oils using PCA according to PC1/PC2. Bud essential oils from Madagascar are represented by white triangle (Group 1) and from Indonesia by black triangle (Group 2).

These results are in agreement with those from Srivastava et al. [20] while still demonstrating the variability among $S$. aromaticum bud essential oils. They mentioned above compared the composition of essential oils from Madagascar with those from India using eugenol (82.6 vs $70.0 \%), \beta$ - caryophyllene (7.2 vs 19.5\%) and eugenyl acetate (6.0 vs $2.1 \%$ ) contents. The comparison of our results using bud oils from Madagascar with those earlier reported by Randriamiharisoa et al. [28], Gaydou et al. [23] and Hector et al. [29] clearly showed similarity to a certain extent in the percentage composition of the main constituents, eugenol (80.6, 77.10 and 74.7 \%), $\beta$ - caryophyllene $(10.5,11.20$ and $7.5 \%)$ and eugenyl acetate $(7.38,6.6$ and $15.8 \%)$.

\subsection{Comparison of the chemical composition of Madagascar and Indonesia leaf essential oils}

Leaf essential oils (28 samples from Madagascar and 4 from Indonesia) were analyzed by GC and 10 constituents were identified and quantified (Table 4). Comparing chemical composition of leaf essential oils from Madagascar with those of Indonesia, variation in the contents of main constituent, eugenol $(80.87-83.58 \%$ vs $75.04-77.54 \%)$, $\beta$ caryophyllene $(11.65-15.02$ vs $17.04-19.53 \%)$ and eugenyl acetate $(0.29-1.45 \%$ vs $0-0.06 \%)$ was observed.

Table 4: Chemical composition (Relative percentage, extreme values) of Madagascar and Indonesia leaf essential oils.

\begin{tabular}{llcc}
\hline & & Group 1 & Group 2 \\
\hline RI & Compounds & Madagascar & Indonesia \\
\hline 1176 & methyl salicylate & $\operatorname{tr}$ & $\operatorname{tr}$ \\
1241 & chavicol & $0-0.12$ & $0.07-0.13$ \\
1348 & eugenol & $80.87-83.58$ & $75.04-77.54$ \\
1375 & $\alpha$-copaene & $0-0.1$ & $0.16-0.24$ \\
1387 & methyl eugenol & $0-0.1$ & $0.15-0.24$ \\
1420 & $\beta$-caryophyllene & $11.65-15.02$ & $17.04-19.53$ \\
1453 & iso-eugenol & $0-0.24$ & $0.08-0.13$ \\
1465 & $\alpha$-humulene & $1.39-1.67$ & $1.93-2.17$ \\
1494 & eugenyl acetate & $0.29-1.45$ & $0-0.06$ \\
1585 & caryophyllene oxide & $0.05-0.55$ & $0.37-0.43$ \\
\hline tr: trace & & &
\end{tabular}

To highlight this variation in the chemical composition of Madagascar and Indonesia leaf essential oils, PCA were performed on the 32 samples combined considering 10 variables (the 10 components identified by GC). The statistical analysis results were as follows: 
The first two principal components (Fig. 5) extracted by PCA explains $71.47 \%$ of the variability, of which $61.91 \%$ was represented by $\mathrm{PC} 1$ and $13.57 \%$ by PC2. PC1 is principally constituted by eugenol (-0.84) and eugenyl acetate (-0.75) with negative correlations and one variable, $\beta$-caryophyllene with positive correlation $(0.96)$.

The PCA according to planes PC1 and PC2 (Fig. 6 and table 4) made it possible to distribute the 32 samples of leaf oil analyzed into two groups:

Group 1 constituted by 28 samples from Madagascar, contains eugenol, $\beta$-caryophyllene and eugenyl acetate at 80.87 $83.58 \%, 11.65-15.02 \%$ and $0.29-1.45 \%$ respectively. Group 2 comprises 4 samples from Indonesia. This group is characterized by lower percentage of eugenol (75.04 - 77.54\%) and higher percentage of $\beta$-caryophyllene (17.04 $19.53 \%$ ) than that of Group 1.

It was reported earlier that cloves leaf essential oil from Madagascar [20] was characterized by higher content of eugenol than from Indonesia [2] (82.0 and 71.0\% respectively). $\beta$-caryophyllene and $\alpha$-humulene were detected at 14.0 and $1.75 \%$, respectively in the leaf oils from Indonesia [2], whereas in the leaf oil from Madagascar [20], these compounds were at 13.0 and $1.5 \%$. It is interesting to note that eugenyl acetate was present in substantial quantity $(0.4 \%)$ in the oil from Madagascar, while this constituent was either absent or present only in traces in the leaf oil from Indonesia.

Similarly, leaf oil from Little Andaman [21] was quite different from those from Indonesia [2] in respect to its eugenol (94.4 vs $71.0 \%), \beta$-caryophyllene (2.9 vs $14.0 \%$ ) and $\alpha$-humulene $(0.36$ vs $1.75 \%)$ contents, respectively. On the other hand, leaf oils from Little Andaman [21] matched to a great extent with the leaf oil from south India reported by Gopalakrishnan et al. [30] in its eugenol content (94.4 and 95.2\%). $\beta$-caryophyllene (2.9\%) and caryophyllene oxide $(0.67 \%)$ were present in the oils from Little Andaman, while either absent or in trace amount in the leaf oils from south India. Eugenyl acetate (1.5\%) was present only in the oils from south India.

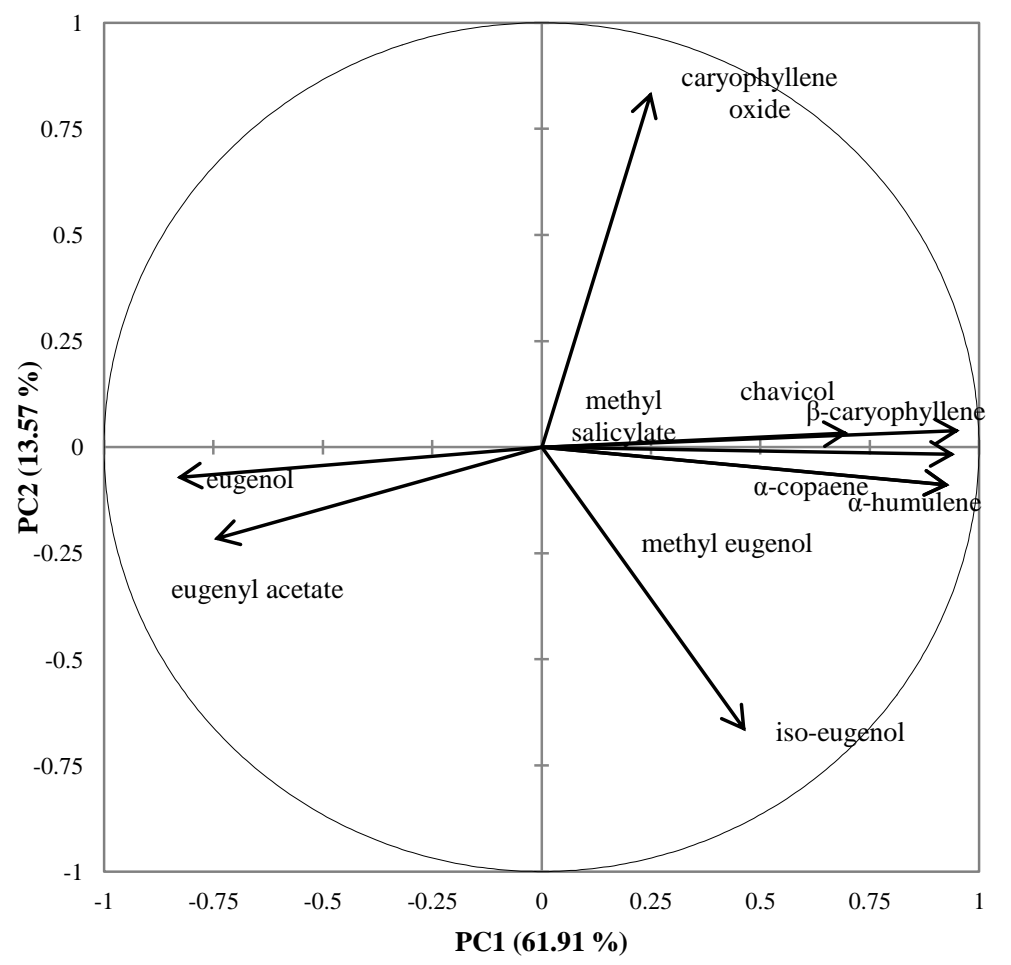

Fig. 5: Circle of correlations of the ten examined variables from leaf essential oils by the first two principal components (PC1/PC2). 


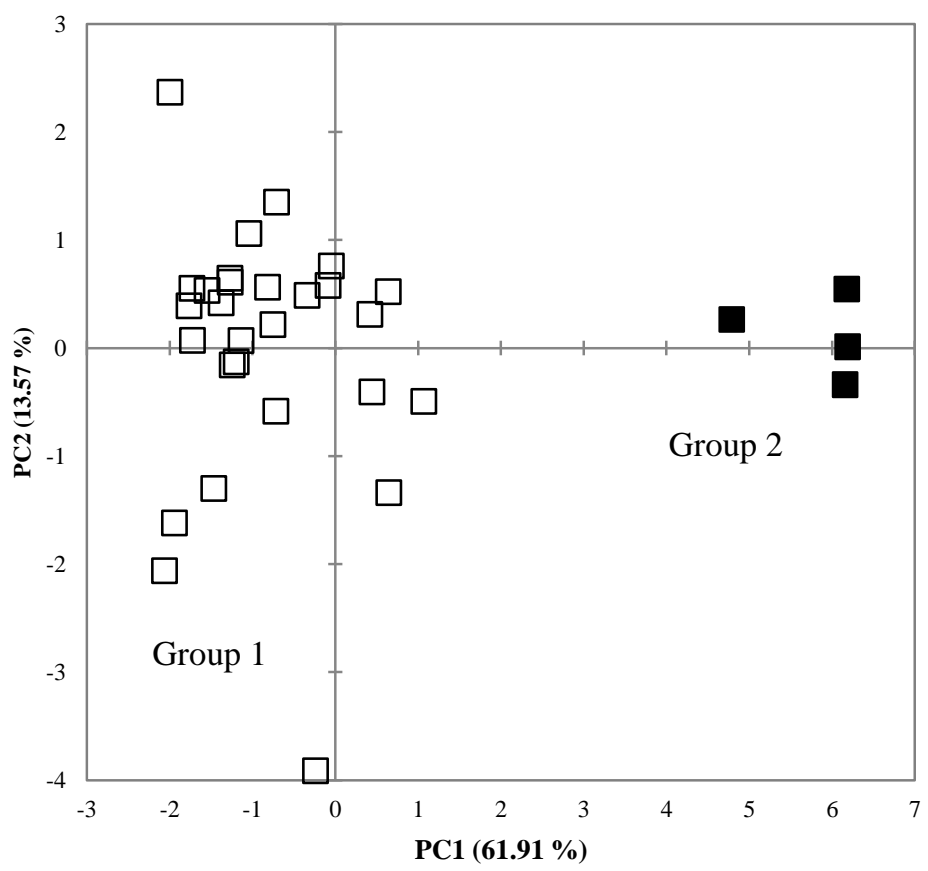

Fig. 6: Graphical representation of the 32 samples of leaf essential oils using PCA according to PC1/PC2. Leaf essential oils from Madagascar are represented by white square (Group 1) and from Indonesia by black square (Group 2).

\subsection{Comparison of the chemical composition of Madagascar, Indonesia and Zanzibar stem essential oils}

Stem essential oils (27 samples from Madagascar, 2 samples from Indonesia and 15 samples from Zanzibar) were analyzed by GC and 10 constituents were identified and quantified (Table 4). The major constituents of Madagascar, Indonesia and Zanzibar stem essential oils were eugenol (91.81 - 96.65\%, 88.76 - 89.28\% and 87.52 - 89.47\%, respectively) and $\beta$-caryophyllene (1.66 - 4.48\%, $7.40-7.75 \%$ and $7.19-9.70 \%)$ (Table 5).

Table 5: Chemical composition (Relative percentage, extreme values) of Madagascar, Indonesia and Zanzibar stem essential oils.

\begin{tabular}{llccc}
\hline & & Group 1 & \multicolumn{2}{c}{ Group 2 } \\
\hline RI & Compounds & Madagascar & Indonesia & Zanzibar \\
\hline 1176 & methyl salicylate & $0-0.56$ & $0.06-0.20$ & $0-0.27$ \\
1241 & chavicol & $0-0.22$ & 0 & 0 \\
1348 & eugenol & $91.81-96.65$ & $88.76-89.28$ & $87.52-89.47$ \\
1375 & $\alpha$-copaene & $0-0.20$ & $0.07-0.16$ & $0-0.27$ \\
1387 & methyl eugenol & $0-0.15$ & $0.03-0.11$ & $0-0.15$ \\
1420 & p-caryophyllene & $1.66-4.48$ & $7.40-7.75$ & $7.19-9.70$ \\
1453 & iso-eugenol & $0-0.80$ & $0.01-0.03$ & $0.01-0.10$ \\
1465 & $\alpha$-humulene & $0.22-0.79$ & $0.93-1.31$ & $0.75-1.08$ \\
1494 & eugenyl acetate & $0.37-2.53$ & $0.07-0.17$ & $0.55-0.88$ \\
1585 & caryophyllene oxide & $0.14-0.6$ & $0.20-0.26$ & $0.25-0.68$ \\
\hline
\end{tabular}

To highlight this variation in the chemical composition of clove stem essential oils, from Madagascar, Indonesia and Zanzibar, PCA were performed on the 44 samples considering 10 variables (10 components identified by GC). The statistical results were as follows:

The first two principal components (Fig. 7) extracted by PCA explains $61.02 \%$ of the variability, of which $43.38 \%$ was represented by $\mathrm{PC} 1$ and $17.63 \%$ by $\mathrm{PC} 2$. PC1 is principally structured by eugenol (-0.93), with a negative correlation and one variable, $\beta$-caryophyllene with positive correlation $(0.95)$.

The PCA according to the PC1 and PC2 planes (Fig. 8 and table 5) made it possible to distribute the 44 stem oil samples analyzed into two groups:

Group 1 composed of all samples coming from Madagascar which is characterized by higher percentage of eugenol $(91.81-96.65 \%)$ and lower percentage of $\beta$ - caryophyllene $(1.66-4.48 \%)$. Group 2, which is constituted by all samples coming from Indonesia and all samples from Zanzibar, is characterized by lower content of eugenol (87.52 $89.76 \%)$ and higher content of $\beta$ - caryophyllene $(7.40-9.70 \%)$ than the first group.

Little literature describes the chemical composition of clove stem oils. Gaydou et al. [23] assumed that clove stem essential oil of is characterized by high eugenol content (up to $70 \%$ ). 


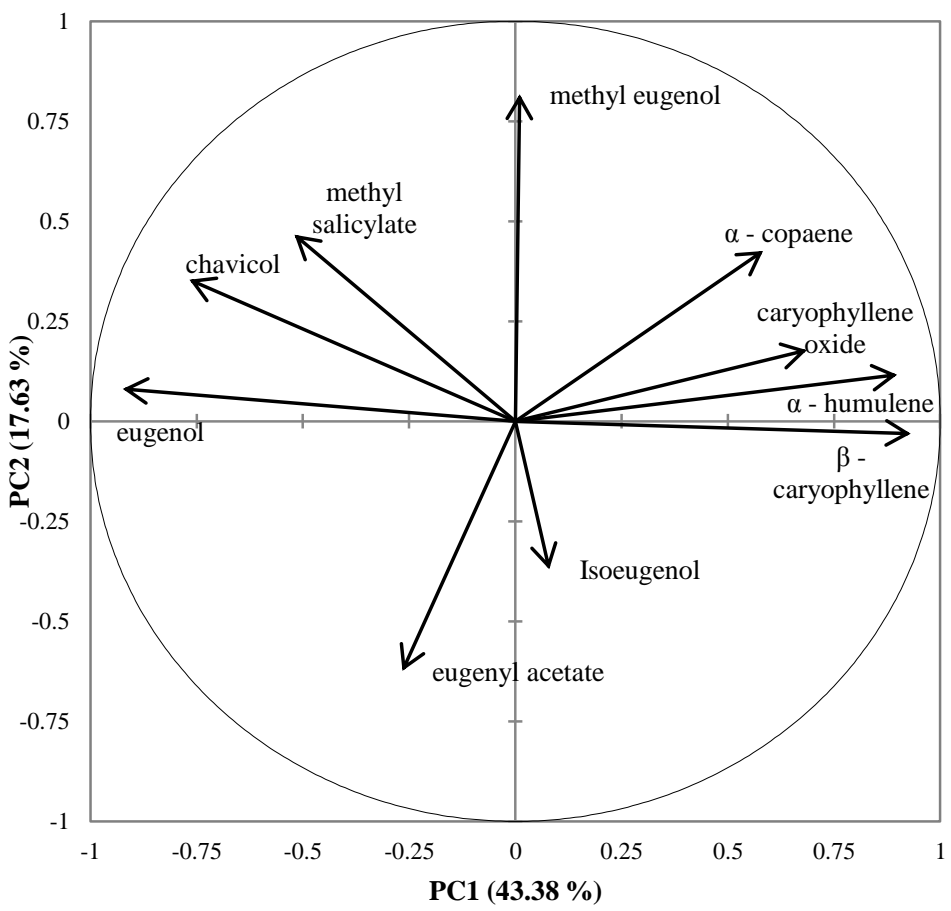

Fig. 7: Circle of correlations of the ten examined variables from stem essential oils by the first two principal components (PC1/PC2).

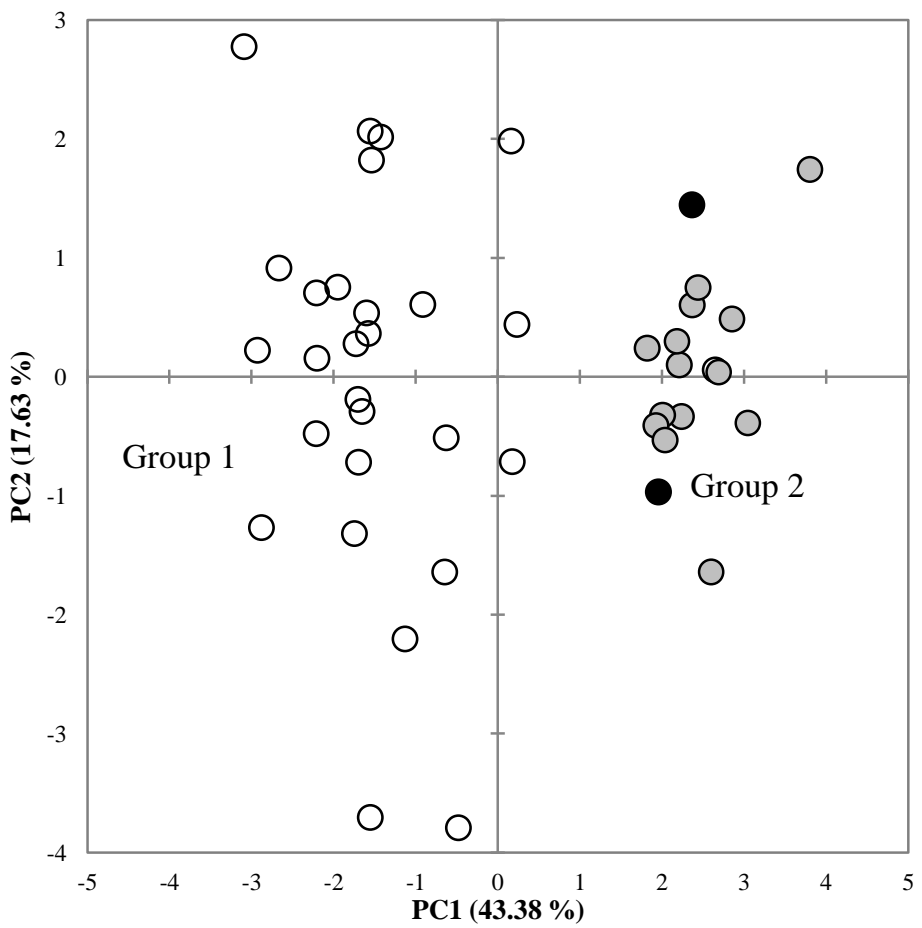

Fig. 8: Graphical representation of the 44 Samples of stem essential oils using PCA according to PC1/PC2. Stem essential oils from Madagascar are represented by white circle (Group 1), from Indonesia by black circle and from Zanzibar by grey circle (Group 2).

\section{Conclusion}

Taking into account our research, we can affirm that it is possible to use the percentage of eugenol, eugenyl acetate and $\beta$-caryophyllene to characterize the essential oil obtained from the different plant parts, bud, leaf and stem. For each plant material, variation in the percentage of these three main constituents was observed according to the geographic origins of sample. 


\section{Acknowledgements}

Financial assistance was gratefully received from the French Ministry of Foreign Affairs (Project PARRUR) and African Union (Project AFS4Food).

\section{References}

[1] A. Ledreux, "Le giroflier à Sainte Marie et à Madagascar", Extrait de l'Agronomie coloniale, Bulletin mensuel de l'Institut Nationale d'Agronomie Coloniale $\mathrm{N}^{\circ} 175$ et 176, (1932), 22 p.

[2] G. Vernin, E. Vernin, J. Metzger, L. Pujol, C. Parkanyi, "GC/MS analysis of clove essential oils. In Spices Herbs and Edible Fungi", Charalambous G (ed.). Elsevier Science: Amsterdam, (1994), 483 - 500.

[3] J. Maistres, "Le giroflier de Madagascar et Zanzibar", Agronomie tropicale, 10, (1955), 415 - 448.

[4] J. Maistres, "Plantes à épices. Paris : Maisonneuve et Larose - Series: Techniques agricoles et productions tropicales", (1964), 32 p.

[5] P.J. Martin, "The Zanzibar clove industry", Economic Botany, 45, 4, (1991), 450-459.

[6] INSTAT, "(Institut National de la Statistique Malgache)", URL: http://www.instat.mg/ [On line]. [14.11.2012], (2012).

[7] M.H. Alma, M. Ertas, S. Nitz, H. Kollmannsberger, "Chemical composition and content of essential oil from the bud of cultivated Turkish clove (Syzigium aromaticum L.)", BioRessources, 2, 2, (2007), 265 - 269.

[8] H.M. Kim, E.H. Lee, S.H. Hong, et al., "Effect of Syzygium aromaticum extract on immediate hypersensitivity in rats", Journal of Ethnopharmacology, 60, (1998), 125 - 131.

[9] L. Cai, C.D. Wu, "Compounds from Syzygium aromaticum possessing growth inhibitory activity against oral pathogens", Journal of Natural Products, 59, (1996), 987 - 990.

[10] M. Friedman, P.R. Henika, R.E. Mandrell, "Bactericidal activities of plant essential oils and some of their isolated constituents against Campylobacter jejuni, Escherichia coli, Listeria monocytogenes, and Salmonella enterica", Journal of Food Protection, 65, (2002), 1545 1560 .

[11] L.R. Beuchat, "Control of foodborne pathogens and spoilage microorganisms by naturally occurring antimicrobials. In Microbial Food Contamination, Wilson CL, Droby S (eds). CRC Press: Boca Raton, FL", (2000), 149 - 169.

[12] H.K. Cressy, A.R. Jerrett, C.M. Osborne, P.J. Bremer, "A novel method for the reduction of numbers of Listeria monocytogenes cells by freezing in combination with an essential oil in bacteriological media", Journal of Food Protection, 66, (2003), 390 - 395.

[13] D. Kalemba, A. Kunicka, "Antibacterial and antifungal properties of essential oils", Current Medicinal Chemistry, 10, (2003), 813 - 829.

[14] F. Chami, N. Chami, S. Bennis, T. Bouchikhi, A. Remmal, "Oregano and clove essential oils induce surface alteration of Saccharomyces cerevisiae", Phytotherapy Research, 19, (2005), 405 - 408.

[15] G.Q. Zheng, P.M. Kenney, L.K.T. Lam, "Sesquiterpenes from clove (Eugenia caryophyllata)", Journal of Natural Products, 55, (1992), 999 1003 .

[16] M. Miyazawa, M. Hisama, "Suppression of chemical mutagen induced SOS response by alkylphenols from clove (Syzygium aromaticum) in Salmonella typhymurium TA1535/pSK1002 umu test.", Journal of Agricultural and Food Chemistry, 49, (2001), 4019 - 4025.

[17] M. Ogata, M. Hoshi, S. Urano, T. Endo, "Antioxidant activity of eugenol and related monomeric and dimeric compounds", Chemical \& Pharmaceutical Bulletin, 48, (2000), 1467 - 1469.

[18] I.K. Park, S.C. Shin, "Fumigant activity of plant essential oils and components from garlic (Allium sativum) and clove bud (Eugenia caryophyllata) oils against the Japanese termite (Reticulitermes speratus)", Journal of Agricultural and Food Chemistry, 53, (2005), 4388 4392.

[19] T. Tworkoski, "Herbicide effects of essential oils", Weed Science, 50, 4, (2002), 425 - 431.

[20] A.K. Srivastava, S.K. Srivastava, K.V. Syamsundar, "Bud and leaf essential oil composition of Syzygium aromaticum from India and Madagascar", Flavour and Fragrance Journal, 20, (2005), 51 - 53

[21] V.K. Raina, S.K. Srivastava, K.K. Aggarwal, K.V. Syamasundar, S. Kumar, "Essential oil composition of Syzygium aromaticum leaf from Little Andaman, India", Flavour and Fragrance Journal, 16, (2001), 334 - 336

[22] G. Razafimamonjison, M. Jahiel, P. Ramanoelina, F. Fawbush, P. Danthu, "Effects of phenological stages on yield and composition of essential oil of Syzygium aromaticum buds from Madagascar", International Journal of Basic and Applied Sciences, 2, 4, (2013), 312 - 318.

[23] E.M. Gaydou, R.P. Randriamiharisoa, "Multidimentional analysis of Gas chromatographic data, application to the differenciation of clove bud and clove stem essential oil from Madagascar", Parfumer \& Flavorist, 12, (1987), 45 - 51.

[24] H.S. Andrianoelisoa, C. Menut, P. Collas-de-Chatelperron, et al., "Intraspecific chemical variability and highlighting of chemotypes of leaf essential oils from Ravensara aromatica Sonnerat, a tree endemic to Madagascar", Flavour and Fragrance Journal, 21, (2006), 833-838.

[25] M. Rakotobe, C. Menut, H.S. Andrianoelisoa, et al., "The bark essential oil composition and chemotaxonomical apparaisal of Cedrelopsis grevei $\mathrm{H}$. Baillon from Madagascar", Natural Product Communications, 3, (2008), 1 - 6.

[26] R. Randrianarivelo, S. Sarter, E. Odoux, et al., "Composition and antimicrobial activity of essential oils of Cinnamosma fragrans", Food Chemistry, 114, (2009), 680-684.

[27] R.P. Adams, "Identification of Essential Oils components by Gas Chromatography / Quadrupole Mass Spectrometry, $4^{\text {th }}$ Ed., Allured Publishing Corporation, Carol Stream", (2007), 1 - 804.

[28] R.P. Randriamiharisoa, E.M. Gaydou, "Sesquiterpenes of clove bud oil Eugenia caryophyllus spreng from Madagascar", Lebensm Wiss u. technology, 20, (1987), 120 - 121.

[29] R.J. Hector, J.E. Simon, "Malagasy Aromatic Plants: Essential Oils, Antioxidant and Antimicrobial Activities", ASNAPP-USA and the New Use Agriculture and Natural Plant Products Program, Rutgers University, 59 Dudley Rd, New Brunswick 08901, NJ, USA (2004).

[30] M. Gopalakrishnan, C.S. Narayanan, A.G. Mathew, "Chemical composition of Indian clove bud, stem and leaf oils", India Perfume, 32, 3, (1988), $229-235$. 